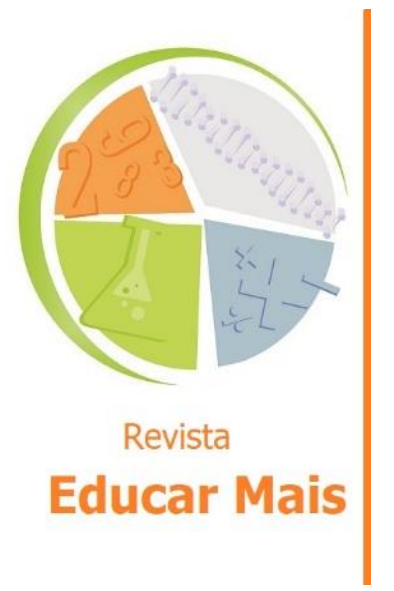

\section{Ensino de microalgas por meio de modelos didáticos: tornando o mundo microscópico visível e significativo ${ }^{i}$}

\author{
Teaching microalgas through teaching models: making the \\ microscopic world visible and meaningful
}

\section{Enseñar microalgas a través de modelos de enseñanza: hacer visible $y$ significado el mundo microscópico}

Laiza Cristina Ricatto da Silva ${ }^{1}$; Adriano Goldner Costa ${ }^{2}$; Michell Pedruzzi

Mendes Araújo ${ }^{3}$; Valéria de Oliveira Fernandes ${ }^{4}$

\title{
RESUMO
}

Esse trabalho objetivou compreender a relevância dos modelos didáticos para o ensino de microalgas em aulas de Ciências de uma escola estadual no munícipio de Santa Teresa, Espírito Santo. Para isso, foram confeccionados e aplicados modelos didáticos, a partir de massa de biscuit, isopor e tinta de tecido, das cinco principais divisões de microalgas: Cyanophyta, Euglenophyta, Dinophyta, Bacillariophyta e Chlorophyta. Foram entregues questionários, antes e após a realização das atividades, para levantar dados sobre o conhecimento dos estudantes acerca da temática abordada. Além da realização de aulas teóricas com a utilização dos modelos didáticos, também foi ministrada uma aula prática em um laboratório do Instituto Federal do Espírito SantoCampus Santa Teresa, onde os estudantes puderam observar as microalgas. Evidenciamos grande potencialidade no uso dos modelos didáticos para o aprendizado de microalgas, destacando-se que eles possibilitaram o contato físico dos alunos com as estruturas representadas. Ademais, destaca-se a importância da realização de aulas práticas para complementar e tornar mais significativa a aprendizagem do conteúdo de microalgas.

Palavras-chave: Microalgas; Modelos didáticos; Aulas práticas; Aprendizagem.

\begin{abstract}
This work aimed to understand the relevance of didactic models for teaching microalgae in Science classes at a state school in the municipality of Santa Teresa, Espirito Santo. For that, didactic models were made and applied, using biscuit dough, styrofoam and fabric paint, of the five main microalgae divisions: Cyanophyta, Euglenophyta, Dinophyta, Bacillariophyta and Chlorophyta. Questionnaires were delivered, before and after the activities were carried out, to collect data on the students' knowledge about the theme addressed. In addition to theoretical classes using didactic models, a practical class was also given in a laboratory at the Federal Institute of Espirito Santo - Campus Santa Teresa, where students could observe the microalgae. We evidenced great potential in the use of didactic models for learning microalgae, highlighting that they made possible the physical contact of the students with the represented structures. In addition, it highlights the importance of conducting practical classes to complement and make the learning of microalgae content more meaningful.
\end{abstract}

Keywords: Microalgae; Didactic models; Practical classes; Learning.

\footnotetext{
1 Prefeitura Municipal da Serra, Serra/ES - Brasil.

2 IFES - Instituto Federal do Espírito Santo, Campus Santa Teresa/ES - Brasil.

3 UFG - Universidade Federal de Goiás- Faculdade de Educação, Goiânia/GO - Brasil.

${ }^{4}$ UFES - Universidade Federal do Espírito Santo, Vitória/ES - Brasil.
} 


\section{RESUMEN}

Este trabajo tuvo como objetivo comprender la relevancia de los modelos didácticos para la enseñanza de microalgas en las clases de Ciencias en una escuela estatal del municipio de Santa Teresa, Espírito Santo. Para ello se realizaron y aplicaron modelos didácticos, utilizando masa de galleta, poliestireno y pintura para tela, de las cinco principales divisiones de microalgas: Cyanophyta, Euglenophyta, Dinophyta, Bacillariophyta y Chlorophyta. Se entregaron cuestionarios, antes y después de la realización de las actividades, para recopilar datos sobre el conocimiento de los estudiantes sobre el tema abordado. Además de las clases teóricas utilizando modelos didácticos, también se impartió una clase práctica en un laboratorio del Instituto Federal de Espírito Santo - Campus Santa Teresa, donde los estudiantes pudieron observar las microalgas. Evidenciamos un gran potencial en el uso de modelos didácticos para el aprendizaje de microalgas, destacando que posibilitaron el contacto físico de los estudiantes con las estructuras representadas. Además, destaca la importancia de realizar clases prácticas para complementar y hacer más significativo el aprendizaje de los contenidos de microalgas.

Palabras clave: Microalgas; Modelos didácticos; Clases prácticas; Aprendizaje.

\section{INTRODUÇÃO}

Na Educação Básica, as microalgas são, geralmente, apresentadas apenas como exemplos de organismos pertencentes aos Reinos Monera e Protista, e como organismos produtores nas cadeias alimentares aquáticas (BRITO; VALLIM, 2014). Todavia, sabe-se que as algas desempenham várias outras funções ecológicas e apresentam diversas aplicações na sociedade que, em inúmeros contextos, não são abordadas nas situações de ensino e de aprendizagem de Ciências e de Biologia.

Alga é um termo genérico, criado por Lineu em 1753, para denominar uma grande variedade de organismos (BICUDO; MENEZES, 2006). As algas são seres clorofilados, macro ou microscópicos, sem diferenciação de raiz, caule ou folhas e predominantemente aquáticas (CHOW et al., 2007). Constituem um grupo de seres unicelulares e multicelulares, com hábitos planctônicos e bentônicos, podendo se apresentar como células isoladas ou em colônias (LOURENÇO, 2006).

As microalgas estão presentes no dia a dia das pessoas e, muitas vezes, essa informação é desconhecida. Sua biomassa pode ser utilizada para elaboração de alimentos, fármacos, cosméticos, alimentos, biodiesel, e elas podem atuar como bioindicadores ambientais, dentre outras aplicações (DERNER et al., 2006). Podem provocar também impactos negativos, como a eutrofização de corpos hídricos, ocasionando drástica redução das concentrações de oxigênio e, consequentemente, a morte de peixes e outros organismos. Ademais, são capazes de contaminar a água com toxinas provenientes de cianobactérias acarretando riscos à saúde pública (PANOSSO et al., 2007).

Mesmo fazendo parte do nosso cotidiano, tendo grande importância para os seres humanos e para outros seres vivos, o conteúdo curricular de algas, como outros da disciplina Biologia, tem sido trabalhado por meio da didática tradicional. Assim, o estudo das algas tem sido restrito, em inúmeros contextos, ao hábito de memorizar os nomes de divisões desse grupo 
e as características biológicas deles, entretanto a relevância ecológica e a importância econômica delas não têm sido enfatizadas.

Nesse sentido, a inclusão de novas metodologias no ensino é necessária, pois, além de atuar com caráter dinamizador, também permite abranger as várias formas de aprender dos estudantes. Outrossim, os modelos didáticos acompanhados de sequências didáticas são uma boa alternativa no ensino de Ciências devido à sua essência prática.

As modalidades de ensino tradicionais, calcadas em aulas expositivas, ainda prevalecem no cenário educacional brasileiro. Desse modo, novidades tecnológicas e novas metodologias de ensino ainda são incipientes em muitas escolas (SILVA; VALLIM, 2015).

No entanto, na atualidade, não há mais espaço para a escola tradicional que apenas objetiva o acúmulo de conhecimentos, pois ela não dá conta de absorver e interpretar a grande quantidade de informações que está exposta rotineiramente nas mídias sociais e em outros canais. Os sistemas de ensino precisam considerar que a sala de aula não se constitui mais o único local de aprendizagem (FERNANDES; SILVA; ARAÚJO, 2020).

Nesse caminho, os modelos didáticos podem facilitar o entendimento de conceitos relacionados às microalgas e promover uma atenção especial a esse grupo de organismos. Destarte, a utilização de materiais didáticos é muito importante, sendo uma metodologia eficaz para introduzir o assunto abordado e também para tornar o estudo de conceitos abstratos mais efetivo e atraente (ADAMY et al., 2015).

Segundo Krasilchik (2008), os modelos são um dos recursos mais utilizados no ensino de Biologia e podem ser aplicados pelos professores para demonstrar determinadas estruturas ou processos. Dessa forma, tornam-se interessantes para tratar de assuntos que envolvam organismos invisíveis ao olho nu, como as algas microscópicas.

O presente estudo foi desenvolvido no município de Santa Teresa, interior do Espírito Santo. Na maioria das escolas públicas desse município, não há laboratórios com equipamentos de microscopia óptica, ou, quando existentes, são rudimentares e disponíveis em quantias insuficientes, o que compromete o acesso adequado ao tema e à visualização das microalgas pelos alunos. Por esse motivo, pensamos em desenvolver modelos didáticos para fazer parte do processo de aprendizagem em microalgas, tendo em vista que a metodologia mais comum e até propícia para isso, ou seja, a utilização de laboratório de aulas práticas e de microscopia óptica é muito difícil de ser aplicada na realidade estudada devido à insuficiência de estrutura física e de equipamentos.

A maior parte dos estudantes desse município provém de regiões rurais próximas aos distritos onde as escolas estão localizadas. Nestas regiões, é comum encontrar lagos artificiais para irrigação de lavouras de café, milho, cana-de-açúcar ou outras culturas. Essas águas "paradas" recebem grande quantidade de descargas orgânicas e inorgânicas, favorecendo o surgimento de microalgas de diversas espécies. Nesse contexto, faz-se mister permitir a esses estudantes o acesso às informações sobre esses organismos microscópicos e sua 
importância ambiental, como forma de cooperar à ampliação do conhecimento e ao desenvolvimento da consciência de preservação.

Ante o exposto, essa pesquisa teve o objetivo de compreender a relevância dos modelos didáticos para o ensino de microalgas em aulas de Ciências. Foi desenvolvida em uma escola de Ensino Fundamental e Médio, localizada no município de Santa Teresa, Espírito Santo.

\section{UTILIZAÇÃO DE MODELOS DIDÁTICOS NAS AULAS DE CIÊNCIAS E BIOLOGIA: UMA BREVE REVISÃO}

Há alguns anos, foram desenvolvidos trabalhos utilizando modelos didáticos como recurso metodológico a ser utilizado para o ensino de Biologia e Ciências, representando diversos processos e estruturas de seres vivos, o que demonstra a viabilidade da utilização deste método nas instituições de educação básica em seus diferentes níveis. No entanto, ressaltase a incipiência de modelos didáticos desenvolvidos para os processos de ensino e aprendizagem das microalgas.

Ao analisarmos o banco de dissertações e teses da Capesii, não localizamos nenhum trabalho que tivesse como foco analítico o ensino de microalgas. O exposto sinaliza uma lacuna que precisa ser preenchida por nós, docentes e pesquisadores de Biologia, acerca do ensino das microalgas. A forma como têm sido conduzidos os processos de ensino e aprendizagem em microalgas precisa ser foco analítico de mais artigos, teses e dissertações. Nesse sentido, justificamos a execução dessa pesquisa.

Tendo em vista a lacuna mencionada no banco de teses e dissertações da Capes, recorremos ao Google Scholar e elencamos seis trabalhos que possuíam relevância teórico-metodológica para essa pesquisa e os trazemos à tona no bojo desse trabalho. O primeiro da presente seleção é o único que se refere a modelos didáticos para o ensino de microalgas.

Adamy et al. (2015) confeccionaram três materiais didáticos relacionados às microalgas para serem apresentados em turmas de Ensino Fundamental e Médio: jogo da memória de microalgas, moldes tridimensionais e também painéis demonstrando o habitat das mesmas. Para confecção do jogo de memória, utilizaram cartas de papel cartão e impressão colorida para melhor visualização; para produção dos moldes didáticos, utilizaram o biscuit. Por fim, os painéis foram montados por uma placa de metal e, sobre ela, foram colocados os modelos didáticos tridimensionais com imãs colados do lado oposto da estrutura mais marcante da alga representada. O objetivo da confecção desses modelos foi facilitar o entendimento de conceitos relacionados às microalgas e de promover uma atenção especial a esse grupo de organismos. Os autores desse trabalho chegaram à conclusão de que a utilização de materiais didáticos é de suma importância, sendo uma alternativa útil para familiarizar o aluno com o assunto tratado e também para tornar o estudo de conceitos abstratos algo mais efetivo e atraente. 
Amaral et al. (2010) elaboraram modelos didáticos para auxiliar a percepção dos conteúdos de Biologia no Ensino Médio em escolas públicas da rede estadual de ensino da cidade de Mossoró - RN. Nesse trabalho, os autores realizaram visitas às escolas para compreender e conhecer os problemas enfrentados pelo professor em sala de aula e, por fim, confeccionaram modelos didáticos relacionados aos conteúdos de citologia: divisão celular, membrana plasmática e célula bacteriana, além de modelos de célula animal e vegetal, genética e histologia. Ao final da aplicação da pesquisa, os autores afirmaram que desenvolveram mais trabalhos utilizando modelos didáticos e buscaram a promoção da "conscientização ambiental", ao utilizarem materiais recicláveis para a montagem dos modelos.

Em 2009, Orlando et al. montaram modelos didáticos para o ensino de conteúdos de biologia celular e molecular para o Ensino Médio em Alfenas - MG. Após a aplicação da pesquisa e avaliação do material didático produzido, os autores puderam corroborar a eficiência do ensino com modelos didáticos, tanto na fixação de conteúdos como para aumentar o interesse dos alunos.

Mello et al. (2007) propuseram a utilização de modelos didáticos para o ensino do conteúdo de proteínas utilizando arames e tampinhas de garrafa PET. Para os autores, a utilização de modelos tridimensionais associados às aulas práticas possibilita encaminhamentos metodológicos numa linha de aprendizagem significativa, resultando em aulas mais agradáveis e interessantes.

Justina et al. (2006) propuseram a construção de modelos didáticos relacionados à temática de genética, particularmente no ensino dos processos de compactação e estrutura do DNA. Utilizaram materiais variados como isopor, espirais de cadernos, fios de cobre, etiquetas e hastes de ferro. Os modelos, juntamente com outros recursos didáticos, foram aplicados em turmas do Ensino Médio, havendo grande aceitação por parte dos alunos. Concluiu-se, no referido trabalho, que a aplicação de modelos didáticos inseridos em uma metodologia de ensino problematizadora facilitou a compreensão sobre a compactação do DNA eucarioto, bem como de sua localização e existência física e como se processa a transmissão das informações hereditárias.

Silva et al. (2009), juntamente com os alunos do $8^{\circ}$ ano de uma escola estadual, construíram modelos didáticos com o objetivo de simular o funcionamento de um olho humano. Ao término da aula, os autores constataram que os alunos tiveram ótima participação, concluindo que transformar o conteúdo teórico em dinâmico foi a melhor maneira de construir uma aprendizagem mais significativa.

\section{LOCAL E SUJEITOS DO ESTUDO}

Esta pesquisa foi realizada em uma turma de $9^{\circ}$ ano - anos finais do Ensino Fundamental de uma escola da rede estadual do município de Santa Teresa-ES, totalizando 22 participantes. Essa turma foi escolhida por estar sendo preparada para cursar o Ensino Médio 
e muitos dos estudantes, após concluírem o Ensino Fundamental, estariam aptos a ingressarem no Instituto Federal do Espírito Santo (Ifes) - Campus Santa Teresa, nos cursos técnicos integrados de Agropecuária e Meio Ambiente. Nesses cursos, o conteúdo de microalgas é trabalhado em diferentes componentes curriculares.

Ademais, este grupo de estudo foi selecionado com o intuito de oferecer maior interatividade com o conteúdo de microalgas no Ensino Fundamental, que é pouco explorado, bem como possibilitar maior aproximação do assunto com a realidade dos alunos, pois integram um contexto rural em que as algas ocorrem nos reservatórios que se situam em suas propriedades. Toda experiência proporcionada aos alunos teve a intenção de contribuir para maior embasamento do conteúdo proposto no ano seguinte, constituinte da disciplina de Biologia no Ensino Médio, permeando outros componentes de maneira interdisciplinar.

\section{ETAPAS QUE ANTECEDERAM A APLICAÇÃO DA SEQUÊNCIA DIDÁTICA}

\subsection{Etapas que antecederam a aplicação da sequência didática}

\subsection{1. $1^{\text {a }}$ Etapa: Coleta de microalgas}

A coleta foi realizada em três pontos relativamente próximos à escola estadual: reservatório na comunidade do Rúdio (distrito de Santa Teresa), setor de suinocultura do Ifes - Campus Santa Teresa e em um trecho do Rio Santa Maria do Doce, que corta o campus.

As amostras foram coletadas com rede de fitoplâncton de $20 \mu \mathrm{m}$, por meio de arrastos horizontais na subsuperfície da coluna d'água, sendo adicionadas em frascos de vidro e preservadas com solução de formalina 4\% (BICUDO; MENEZES, 2006).

Após as coletas, as análises foram realizadas no Laboratório de Ecologia e Biodiversidade do Ifes - Campus Santa Teresa, a partir da montagem de lâminas e visualização em microscópio óptico em aumento de 400 (quatrocentas vezes). As microalgas observadas em cada ambiente foram identificadas e, posteriormente, serviram de base para a seleção das espécies utilizadas na confecção dos modelos didáticos. Além das microalgas encontradas nas coletas, foi utilizado o laminário disponível no Laboratório de Ecologia e Biodiversidade do Ifes para complementação do material biológico, uma vez que as coletas não possuíam todos os táxons que seriam utilizados como referência para os modelos didáticos.

\subsection{2. $2^{a}$ Etapa: Identificação da divisão e do gênero das algas presentes nas amostras}

Com relação aos grupos de algas presentes nas amostras coletas, destacaram-se dois principais: as euglenófitas (divisão Euglenophyta), representadas pelas algas do gênero Phacus (Figura 1), encontradas na amostra do lago da Suinocultura; e as diatomáceas (divisão Bacillariophyta), representadas por gêneros diversos da ordem Pennales (Figura 2), provenientes da amostra do Rio Santa Maria do Doce. Na comunidade do Rúdio, observouse uma grande quantidade de cianobactérias (divisão Cyanophyta), nas formas coloniais. 
Figura 1 - Alga do gênero Phacus encontrado nas amostras coletadas no lago do Setor de Suinocultura do IFES. Fonte: Acervo pessoal.

Figura 2 - Diatomácea da ordem Pennales encontrada na amostra coletada no Rio Santa Maria do Doce. Fonte: Acervo pessoal.

\subsubsection{3a Etapa: Construção dos modelos didáticos}

A construção dos modelos didáticos seguiu a mesma metodologia proposta por Brito e Vallim (2014) que utilizaram basicamente a porcelana fria (massa de biscuit), tinta de tecido e isopor (Figura 3).

Os modelos tiveram, aproximadamente, de 15 (quinze) a 20 (vinte) centímetros, em seu maior comprimento, seguindo os critérios de Cerqueira e Ferreira (1996). As peças foram preparadas da forma mais fidedigna possível, entretanto, por se tratar de representações de organismos microscópicos, o tamanho utilizado foi de alguns milhares de vezes maior do que o normal, com o intuito de facilitar a compreensão dos aspectos morfológicos e estruturais das microalgas. 


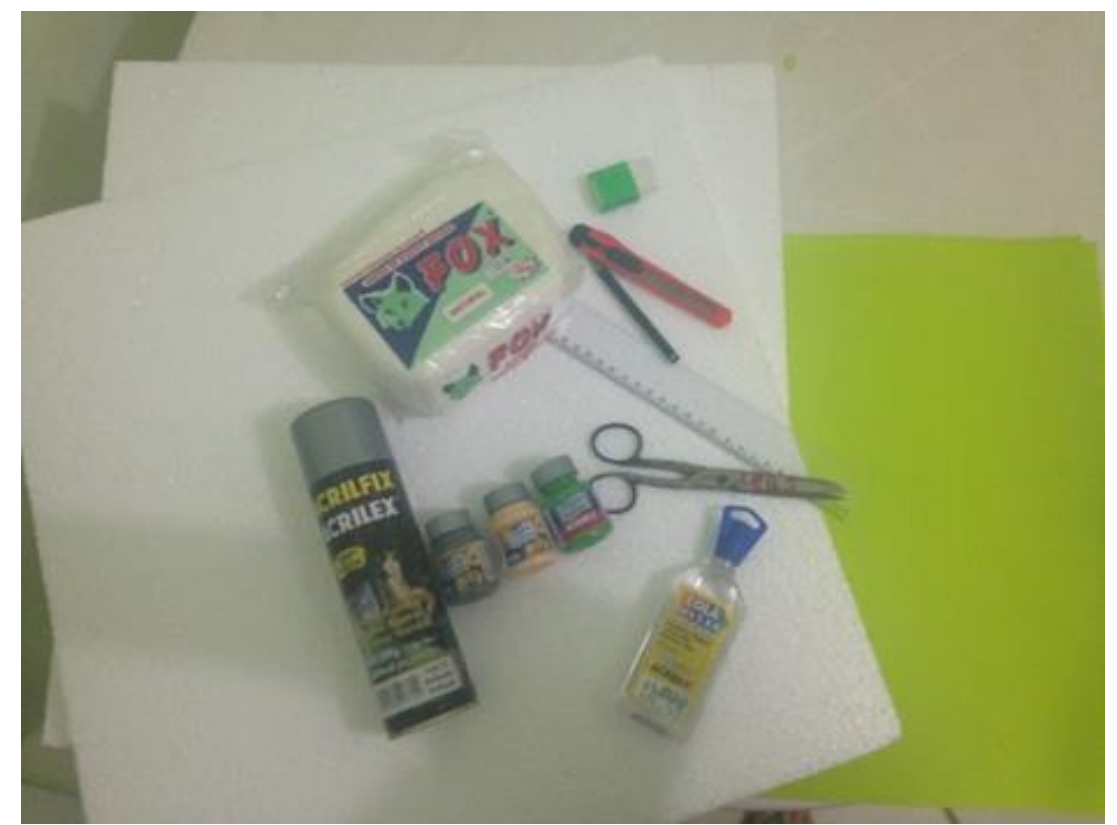

Figura 3 - Materiais utilizados na confecção dos modelos didáticos. Fonte: Acervo próprio

A montagem dos modelos (Figura 4) foi realizada utilizando algumas folhas de isopor de 5 $\mathrm{cm}$. (centímetros) de espessura, que serviram de base para a fixação das peças. Após o posicionamento dos modelos didáticos sobre as folhas de isopor, os mesmos foram colados e identificados com informações acerca do grupo taxonômico ao qual a alga pertencia, bem como o gênero e as principais importâncias ambientais e econômicas.

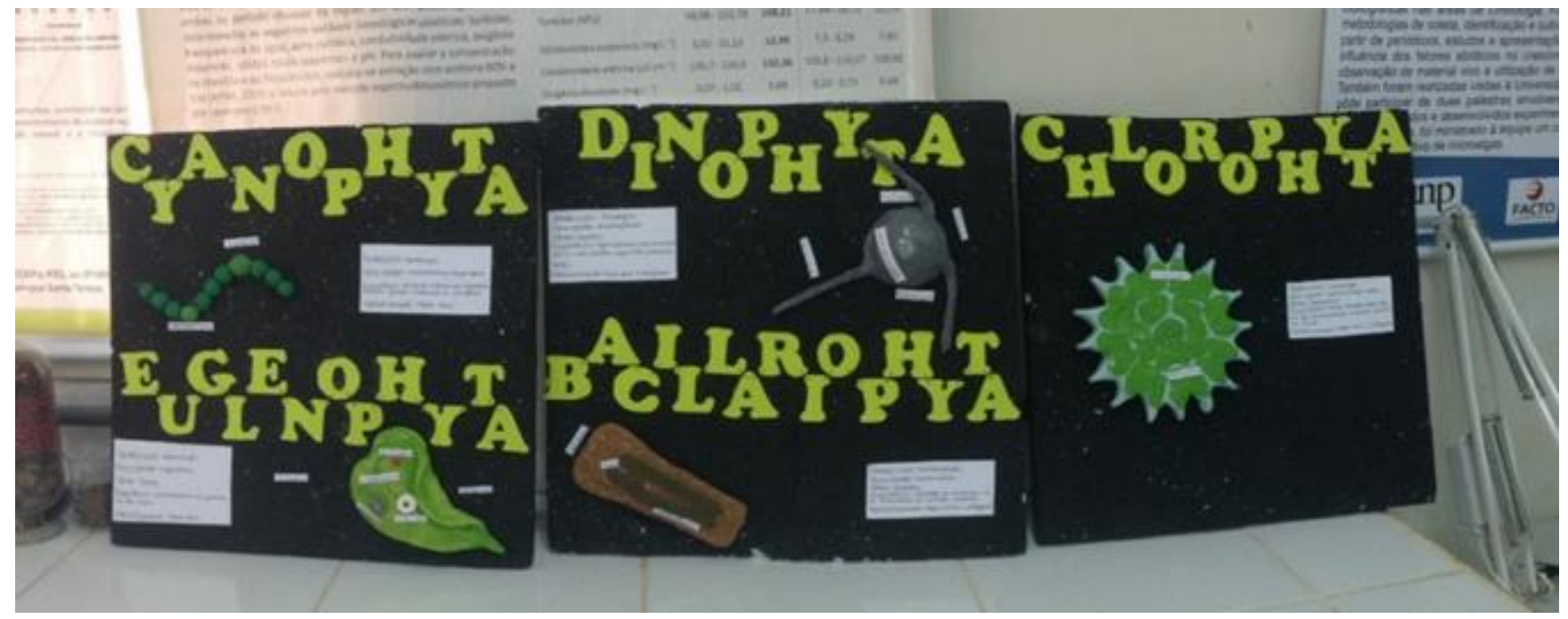

Figura 4 - Modelos didáticos prontos. Fonte: Acervo pessoal

Foram escolhidas espécies representantes de cada uma das principais divisões de microalgas: Cyanophyta, Euglenophyta, Dinophyta, Bacillariophyta e Chlorophyta, de acordo com o sistema de classificação de Round et al. (1990). Os táxons foram escolhidos baseados na facilidade de encontrá-los in natura. 


\section{RESULTADOS}

\subsection{A proposição de uma sequência didática para o ensino de microalgas}

As sequências didáticas são compostas por várias atividades, mediadas por um professor e proporcionam ao aluno um aprofundamento crescente do tema discutido, ao trabalhar o tema utilizando-se de várias estratégias durante algum tempo. Isso favorece a aprendizagem significativa de todo o grupo (KOBASHIGAWA, 2008).

Partimos do pressuposto de que uma sequência de ensino é uma estratégia que permite a realização de investigações em sala de aula, constituindo assim, maneiras de auxiliar na compreensão dos conteúdos de Ciências, bem como uma forma de desenvolver a Alfabetização Científica (AC) dos alunos a partir de diferentes atividades, como aula de campo, experimentos, leituras de diversos gêneros, dentre outras (CARVALHO, 2013).

Também entendemos que, por meio das sequências didáticas, docentes e alunos serão capazes de superar metodologias tradicionais de ensino e aprendizagem para vivenciar propostas mais envolventes e interativas. Desse modo, será permitido a eles o acesso e o uso de conhecimentos de gerações anteriores, bem como os seus próprios (CARVALHO, 2013).

Tendo como referência o que dizem Kobashigawa (2008) e Carvalho (2013), partimos para o desenvolvimento de uma sequência didática para potencializar os processos de ensino e aprendizagem em microalgas. Para realização das atividades, ocorreram cinco encontros com uma turma de $9^{\circ}$ ano- anos finais do Ensino Fundamental.

Em um primeiro momento, foi entregue um documento, o Termo de Consentimento Livre e Esclarecido - TCLE, que informava e esclarecia ao participante da pesquisa os procedimentos da mesma, de maneira que pudesse tomar sua decisão, de forma justa e sem constrangimentos, sobre sua participação no projeto. Também neste dia, foi entregue à turma um questionário de diagnóstico inicial.

No segundo momento, foram realizadas três aulas teóricas (figura 5). Optou-se por trabalhar a partir dos grupos de microalgas mais basais, evolutivamente falando, até os mais complexos. Sendo assim, a primeira aula compreendeu os grupos Cianophyta e Euglenophyta; a segunda, os grupos Dinophyta e Bacillariophyta e, por fim, o grupo Chlorophyta.

Em todas as aulas, a seguinte sequência foi adotada: primeiramente, as características dos grupos de microalgas eram apresentadas utilizando os modelos didáticos. Posteriormente, a importância ecológica e potencial econômico foram exploradas por meio de uma aula expositiva e dialogada, com auxílio de um Datashow. Por último, os estudantes tiveram a oportunidade de utilizar os modelos didáticos para responder às questões dos exercícios referentes aos grupos de algas estudados em cada aula. 


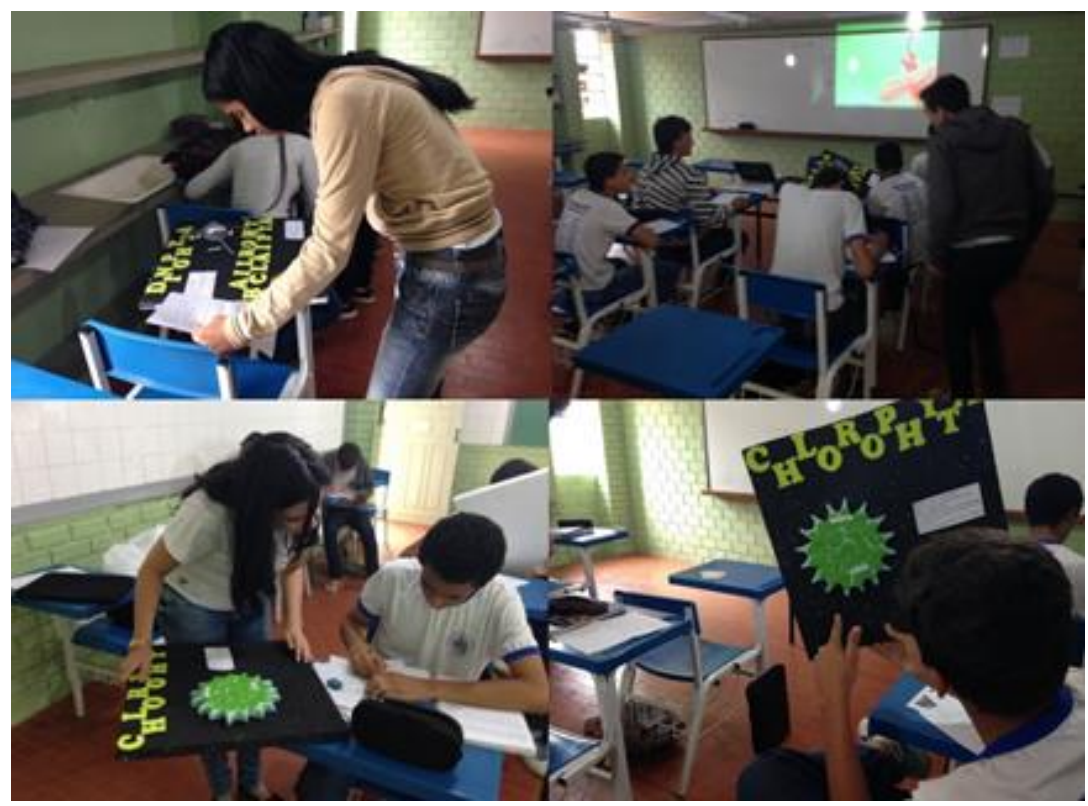

Figura 5 - Aulas teóricas utilizando modelos didáticos. Fonte: Acervo próprio.

Em um terceiro e último momento, a turma de $9^{\circ}$ ano foi até o Laboratório de Ecologia e Biodiversidade do Ifes - campus Santa Teresa (Figura 6).

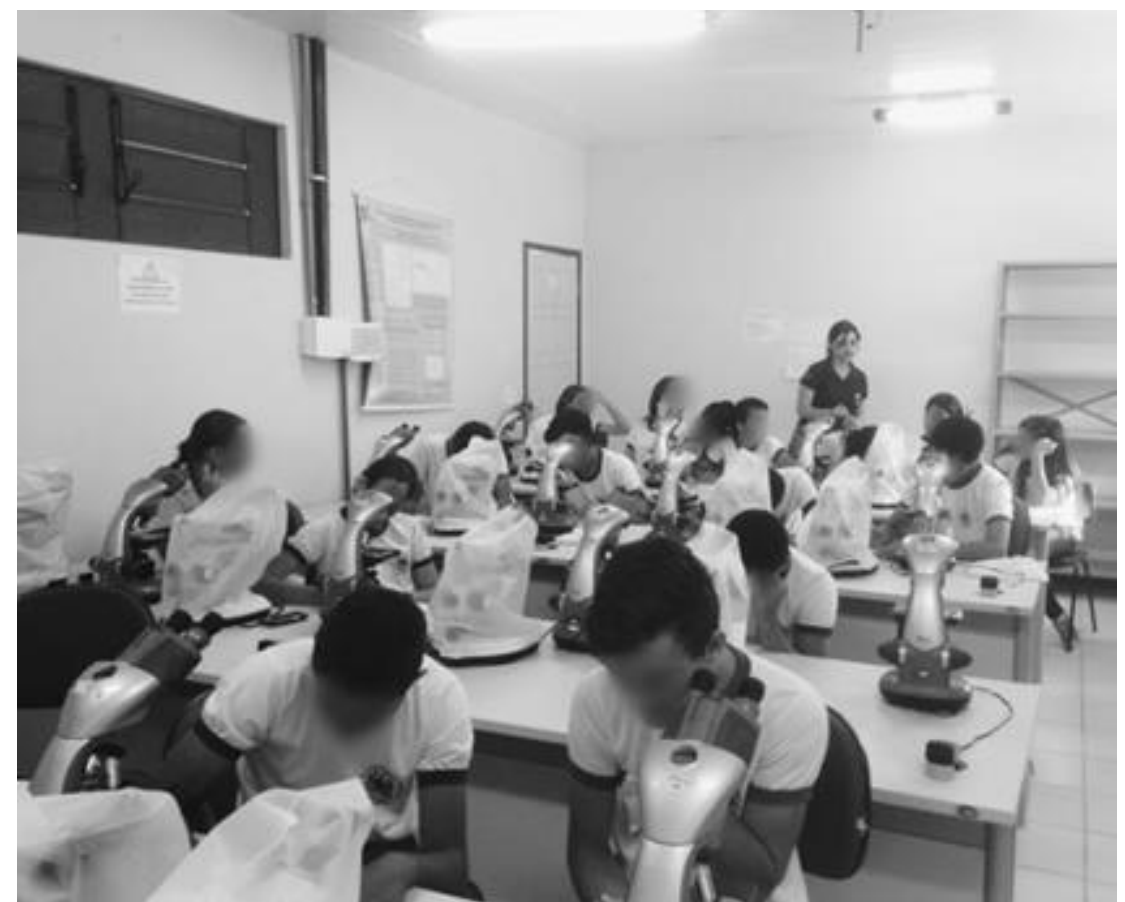

Figura 6 - Estudantes em aula prática no Laboratório de Ecologia e Biodiversidade do IFES. Fonte: Acervo próprio

O objetivo principal desta aula era comparar as microalgas que os estudantes estavam visualizando no microscópio ótico, com as microalgas dos modelos didáticos. Primeiramente, foram explicitados aos estudantes os métodos utilizados para as coletas de microalgas, como a rede de fitoplâncton e os equipamentos para medição de parâmetros limnológicos como o condutivímetro portátil e o potenciômetro digital portátil. Esse esclarecimento foi importante 
para demonstrar aos alunos o quanto os fatores abióticos podem influenciar as comunidades de microalgas existentes.

Depois, os alunos revezaram-se entre os microscópios para visualização dos microrganismos. Cada aluno esquematizou as microalgas que conseguiu visualizar (Figura 7). Ao final da aula foi entregue um questionário, a fim de avaliar a opinião dos estudantes sobre a utilização de modelos didáticos para o ensino de microalgas.

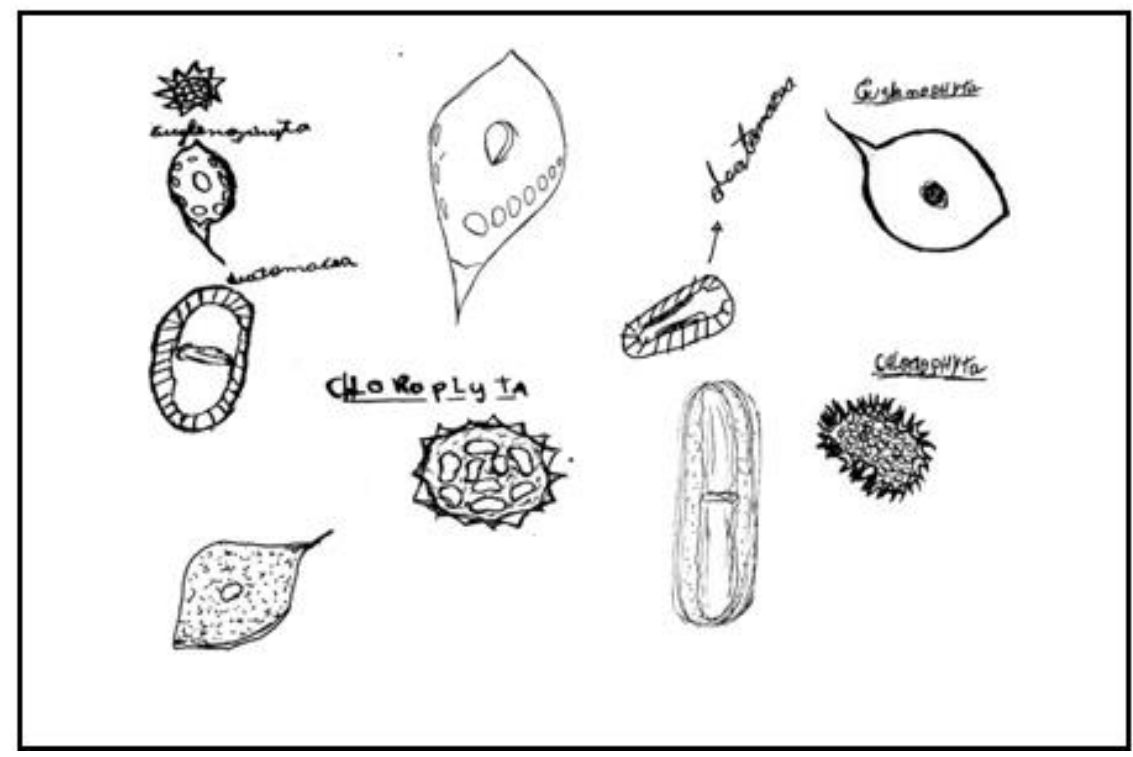

Figura 7 - Desenhos esquemáticos de microalgas feitos pelos alunos, durante observação em microscópio óptico. Fonte: Acervo próprio

\subsection{Análises das respostas dos estudantes aos questionários e exercícios propostos}

Nessa seção, analisamos as respostas dos estudantes relacionadas aos questionários e aos exercícios realizados.

\subsubsection{Questionário 1 - Diagnóstico inicial}

No primeiro instrumento de coleta de dados, realizou-se um diagnóstico sobre os conhecimentos prévios dos estudantes com relação às algas e suas características.

Em uma das perguntas, foi questionado se os estudantes já haviam observado algas. A maior parte deles respondeu que já viu em sites na internet (35\%), em livros didáticos (31\%), em microscópio (13\%), em ambientes aquáticos (9\%) e em outros ambientes (6\%). 13\% dos alunos afirmaram terem conhecido microalgas por meio de microscópio (provavelmente, em alguma situação proporcionada pela própria escola). Isso evidencia a presença de poucos recursos materiais que contribuem ao ensino nas escolas de ensino público o que, mais uma vez, justifica a utilização dos modelos didáticos para ampliação e acesso ao conhecimento.

Também foi observada forte tendência de se relacionar as algas às plantas e ao mar, como é senso comum. Muitos alunos responderam que as algas eram "plantas que aparecem no mar", "planta aquática" ou "plantas que servem de alimento para os peixes"; todas essas respostas se referiam às algas encontradas nas praias. Devido à coloração esverdeada de 
algumas delas, há essa associação com as embriófitas, ou como são conhecidas vulgarmente: plantas verdadeiras.

O melhor resultado foi obtido nas perguntas sobre a organização celular e a quantidade de células que as algas poderiam apresentar. A maioria dos alunos (70\%) respondeu que as algas poderiam ser unicelulares e pluricelulares e $50 \%$ deles afirmaram que as algas eram organismos eucariontes.

Em relação à importância ecológica das algas, 42,8\% dos estudantes afirmaram que estes seres produzem oxigênio. Na Educação Básica, as algas são comumente relacionadas como produtoras de oxigênio e como organismos ocupantes das bases das cadeias alimentares. Esses dois papéis são bem explorados durante o $7^{\circ}$ ano do Ensino Fundamental, quando se aborda o conteúdo sobre algas e ecologia, o que pode explicar tal percentagem. Apesar disso, 33,3 \% dos alunos não conseguiram citar uma importância ecológica das algas e apenas $23,8 \%$ as relacionaram como bases das cadeias alimentares dos seres vivos.

Quanto aos prejuízos e impactos que as algas poderiam causar aos seres vivos e aos seres humanos, novamente, a maior parte dos alunos não soube responder (25\%), seguidos por respostas como: "depende do tipo de alga" (16,6\%), "maré vermelha" (16,6\%), "poluição" $(16,6 \%)$, "mata os peixes" $(16,6 \%)$ e "doenças" (8,3\%). Os livros didáticos trazem exemplos de problemas ambientais causados pelas algas, sendo um deles, muito mencionado, a maré vermelha, que os alunos citaram nas respostas. Quanto à poluição e morte de peixes, podese supor que os estudantes já tenham presenciado o processo de eutrofização de ambientes aquáticos, com consequente mortandade de organismos, como pode ocorrer nos reservatórios construídos artificialmente em propriedades rurais da região.

Sobre a importância econômica das algas, a maioria dos estudantes afirmou que elas são utilizadas na alimentação, possivelmente pelo fato de elas estarem cada vez mais presentes na mesa dos brasileiros. 0 exposto evidencia a influência da culinária oriental (na comida japonesa, por exemplo, se utiliza o nori, produzido a partir de algas vermelhas), atualmente mais acessível à população do Brasil.

\subsubsection{Exercício: Grupos Cyanophyta e Euglenophyta}

Conforme descrito anteriormente, foram realizadas aulas teóricas utilizando os modelos didáticos e ao final delas, entregues exercícios relacionados ao tema abordado.

Foram 172 (53\%) acertos e 151 erros (53\%), em 323 sentenças respondidas por 14 estudantes. Percebe-se certa confusão por parte dos estudantes em conceitos como: heterócitoiii, acineto ${ }^{i v}$, estigmal ${ }^{v}$, eucarionte ${ }^{v i}$ e procarionte ${ }^{v i i}$, por exemplo. Provavelmente, foi a primeira vez que os alunos tiveram contato com esses termos e, devido ao pouco tempo que tiveram para responder às questões, podem ter confundido e disposto as palavras nas sentenças erradas. 


\subsubsection{Exercício: Grupos Dynophyta e Bacillariophyta}

Algumas das respostas dos estudantes estão dispostas abaixo (Figuras 8 e 9). Com relação aos exercícios focados nos grupos Dinophyta e Bacillariophyta, constatou-se que o predomínio de acertos dos estudantes neste exercício pode ter sido reflexo da procura e da consulta dos modelos didáticos durante a aula.

Além disso, os alunos demonstraram grande curiosidade acerca dos dinoflagelados, realizando perguntas sobre as marés vermelhas, as toxinas etc. Em relação às diatomáceas, os estudantes tiveram um pouco de dificuldade em entender o que era a substância silica. Em contrapartida, ficaram impressionados ao saber que as diatomáceas estão presentes na fabricação de pastas de dentes e em explosivos como a dinamite.

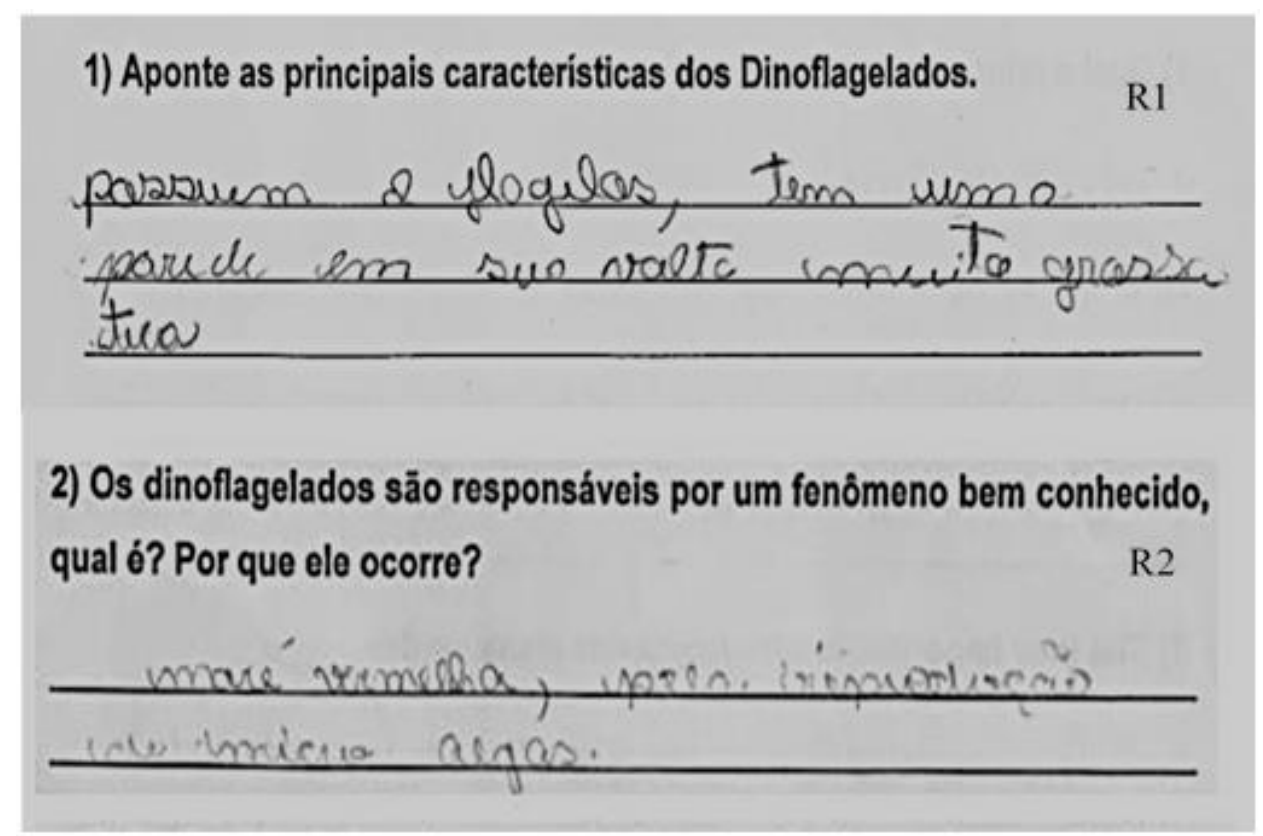

Figura 8 - Respostas apresentadas por alguns estudantes referentes às questões 1 e 2 do exercício (dinoflagelados). R1: "Possuem 2 (dois) flagelos, tem uma parede em sua volta muito grossa (teca)". R2: "Maré vermelha, pela reprodução de microalgas". Fonte: Acervo próprio

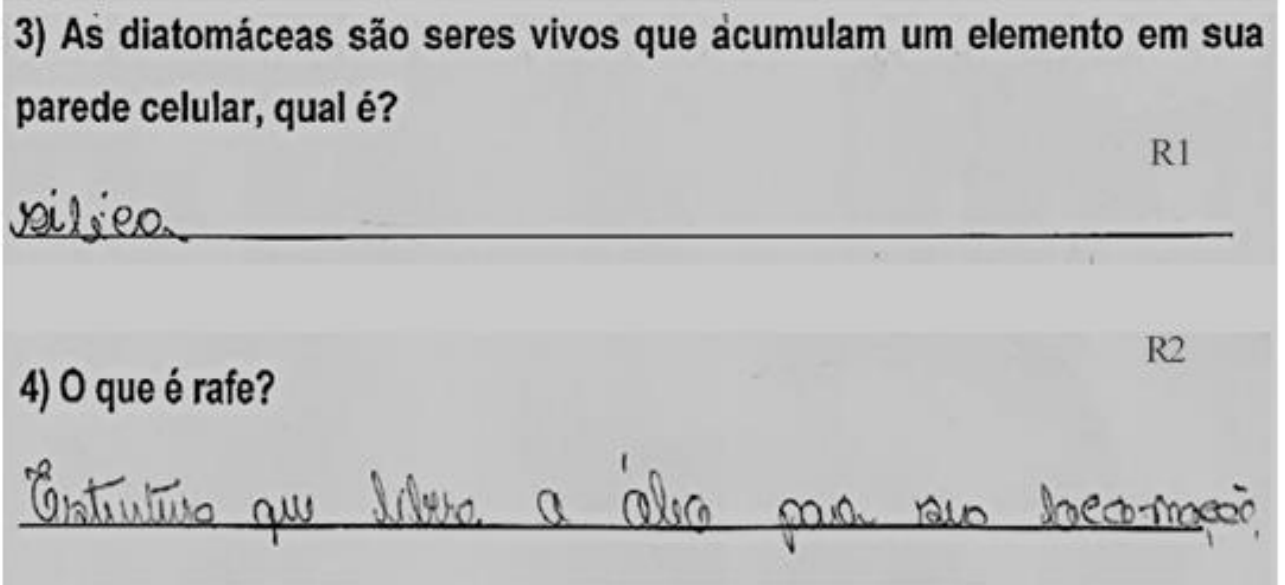

Figura 9 - Respostas apresentadas por alguns estudantes referentes às questões 3 e 4 do exercício (diatomáceas). R1: "Sílica". R2: "Estrutura que libera óleo para sua locomoção". Fonte: Acervo próprio. 


\subsubsection{Exercício: Grupo Chlorophyta}

Já no exercício III, além de apresentarem respostas coerentes, os alunos esquematizaram a alga representada no modelo didático em seu habitat natural (Figura 10). Este resultado foi interessante uma vez que os estudantes conseguiram fazer a conexão destas algas aos ecossistemas em que são encontradas, indicando a relevância da utilização dos modelos.

1) Qual o principal pigmento das algas verdes?

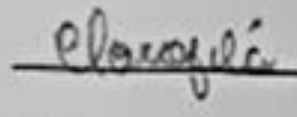

2)Por que as algas verdes săo consideras as "ancestrais" das plantas?

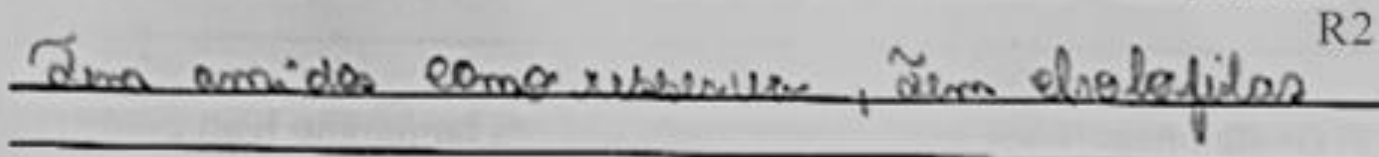

3) Cite uma importância econômica das algas verdes.

Girdiol

4) Esquematize uma microalga verde e 0 ambiente onde ela está presente.

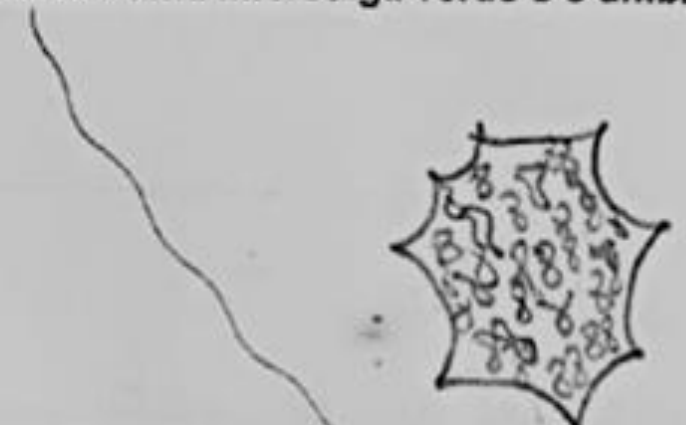

Figura 10 - Exercício sobre algas verdes respondido por um estudante. R1: "Clorofila". R2: "Tem amidos como reserva. Tem clorofilas". R3: "Biodiesel". Fonte: Acervo próprio.

\subsubsection{Questionário de aula prática}

De modo geral, os alunos manifestaram boa receptividade em relação à aula prática no laboratório e se demonstraram animados com as novas descobertas realizadas.

De acordo com as respostas dos questionários (Figura 11 e 12), todos os alunos participantes da pesquisa aprovaram a utilização dos modelos didáticos como alternativa metodológica para trabalhar a temática de microalgas nas aulas de Ciências. 


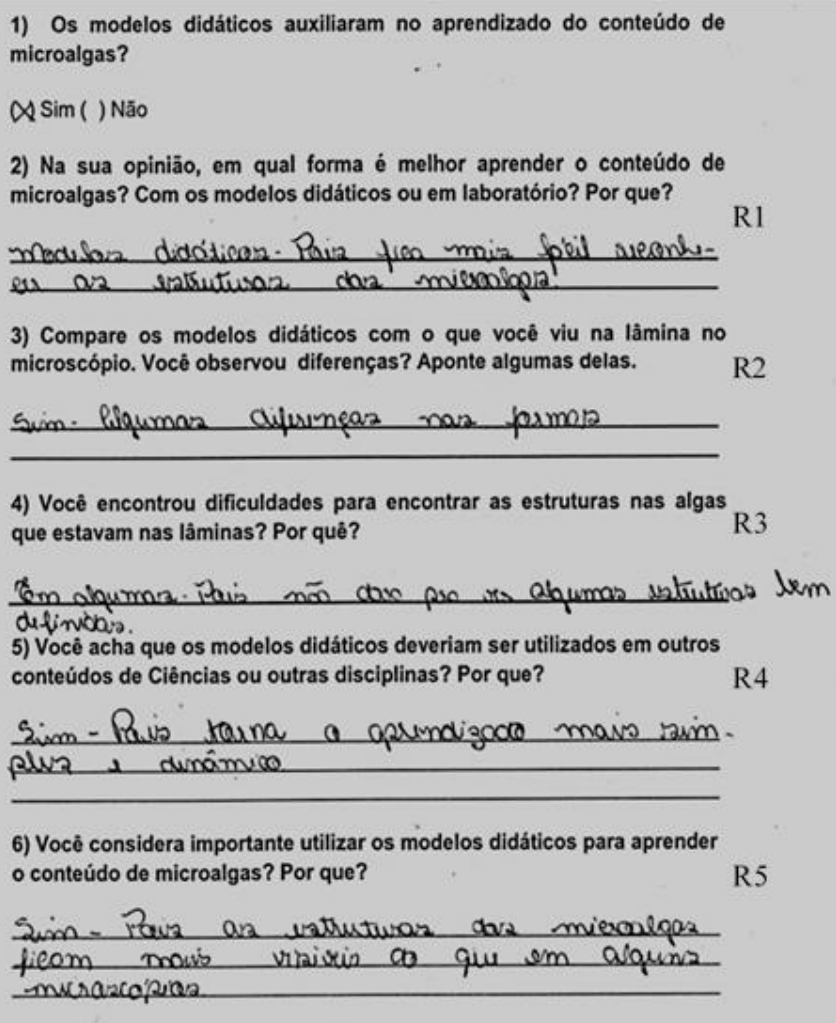

Figura 11 - Respostas de um dos participantes ao questionário final - Favorável ao uso de modelos didáticos. R1: "Modelos didáticos. Pois fica mais fácil reconhecer as estruturas das microalgas." R2: "Sim. Algumas diferenças nas formas." R3: "Em algumas. Pois não dá pra ver algumas estruturas bem definidas." R4: "Sim. Pois torna o aprendizado mais simples e dinâmico." R5: "Sim. Pois as estruturas das microalgas ficam mais visíveis do que em alguns microscópios." Fonte: Acervo próprio.

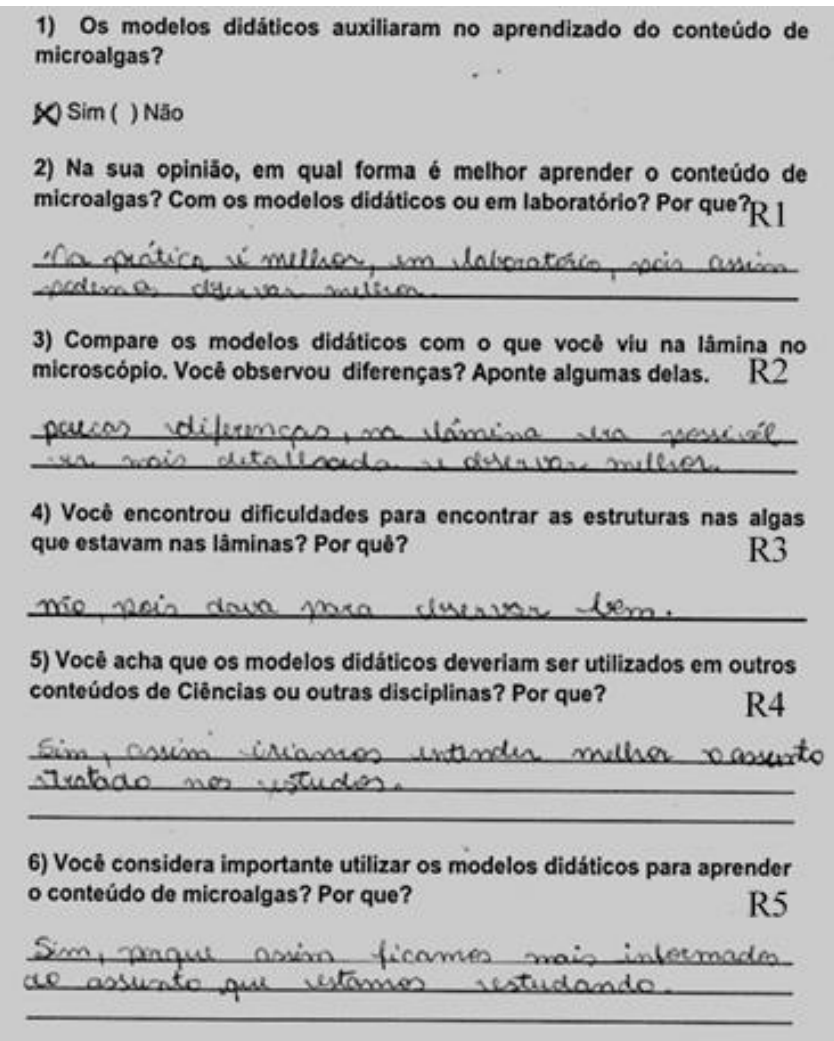

Figura 12 - Respostas de um dos participantes ao questionário final - Favorável às aulas práticas. R1: "Na prática é melhor, em laboratório, pois assim podemos observar melhor." R2: "Poucas diferenças, na lâmina era possível ver mais detalhada e observar melhor." R3: "Não, pois dava para observar bem." R4: "Sim, assim iriamos entender melhor o assunto tratado nos estudos." R5: "Sim, porque assim ficamos mais informados do assunto que estamos estudando." Fonte: Acervo próprio. 
Apesar de muitos alunos destacarem a relevância dos modelos didáticos, a maioria deles afirmou que a aula em laboratório contribuiu mais ao aprendizado do conteúdo de microalgas. Por esse prisma, Andrade e Massabni (2011) destacam que as atividades práticas permitem aprendizagens que a aula teórica, às vezes, não permite. Esse depoimento evidencia a importância dessa modalidade na educação básica, pois, segundo Rosa (2012), as aulas práticas trazem inovação e promovem dinâmicas em que o aluno deixa de ser ouvinte e passa a ser integrador dos processos de ensino e aprendizagem.

Contudo, alguns estudantes também consideraram que os modelos didáticos seriam a melhor forma de aprender o conteúdo de microalgas, destacando a questão do tato, melhor visualização de estruturas, facilidade de acesso aos modelos, dentre outros fatores.

De modo geral, os modelos didáticos tiveram ótima receptividade pelos alunos. Muitos estudantes justificaram o uso de tal ferramenta por serem "mais interessantes", por "facilitarem o entendimento", por serem "mais acessíveis", "dinâmicos" etc.

O que foi destacado pelos estudantes é corroborado por Adamy et al. (2015). De acordo com os autores:

Devido à dificuldade de se ensinar certos conceitos da Biologia, especialmente em relação às microalgas, jogos e modelos didáticos podem ser uma alternativa viável para aprimorar o processo de ensino e aprendizagem, sendo vantajoso devido ao baixo custo para produção e pelo fato de serem adaptados pelos próprios alunos, visto que são jogos manuais (ADAMY et al., 2015, p. 59).

Nesse sentido, percebe-se a importância de se investir em metodologias diferenciadas para haver maior interesse por parte dos estudantes nas temáticas abordadas no ensino de Ciências. Como as microalgas eram organismos desconhecidos pela maioria dos alunos, os modelos didáticos trouxeram, junto com a demonstração das formas e estruturas dos grupos abordados, informações relevantes para a construção do conhecimento escolar.

Nesse caminho, é imprescindível que os professores busquem propiciar aos estudantes as condições para que se desenvolvam conceitos, atitudes e habilidades, superando ações puramente mecânicas em prol de ações intelectuais (CARVALHO, 2013).

\section{CONSIDERAÇÕES FINAIS}

A utilização dos modelos didáticos, ao longo dos encontros realizados com os estudantes do 90 ano participantes dessa pesquisa, mostrou muita potencialidade metodológica para o ensino de microalgas. De modo geral, os estudantes demonstraram interação com os modelos de microalgas confeccionados, o que despertou a curiosidade e o interesse dos sujeitos pelo assunto proposto.

A partir dos dados extraídos do questionário inicial da pesquisa, percebeu-se que a maioria dos estudantes apresentou conhecimento muito simples e superficial acerca das microalgas, principalmente, em relação à importância ecológica dos grupos e aos impactos ambientais que eles podem causar. Contudo, ao longo do trabalho, foi observado o interesse do grupo 
pelo tema. Nas aulas teóricas com os modelos didáticos, os estudantes buscaram sanar suas dúvidas e, no momento em que realizaram os exercícios, consultaram os modelos didáticos para responderem às perguntas. Essas percepções foram corroboradas por meio dos percentuais encontrados para as respostas dos questionários, evidenciando que o uso dos modelos didáticos foi importante para os processos de ensino e aprendizagem.

Salienta-se, por meio desse estudo, que as aulas em laboratório também são metodologias basilares para o ensino de Ciências e de Biologia, pois constituem uma forma de o estudante obter contato direto com o conteúdo em estudo.

Por tratar-se de um ambiente novo para os estudantes, observou-se maior interesse pela aula realizada no laboratório do Instituto Federal do Espírito Santo- Ifes do Campus Santa Teresa, quando comparada às aulas teóricas em sala com os modelos didáticos na escola de origem. Além da mudança de "cenário", os alunos também tiveram a oportunidade de observar, de forma mais interessante, ao microscópio, as morfologias e diferentes estruturas das algas. Todavia, tanto os estudantes quanto o professor de Ciências concordaram que a utilização dos modelos didáticos, como alternativa metodológica, foi viável para o ensino do conteúdo de microalgas e favoreceu melhor compreensão do assunto, pois os modelos didáticos apresentaram, em maiores detalhes, as formas e estruturas dos grupos estudados. Ademais, tais modelos, que apresentem alto relevo e texturas distintas, podem ser aplicados na educação especial numa perspectiva inclusiva, sobretudo aos alunos com deficiência visual, que podem utilizá-los para potencializar a sua aprendizagem acerca das microalgas.

Por fim, conclui-se que a utilização dos modelos didáticos apresentou resultado positivo nos processos de ensino e aprendizagem do conteúdo de microalgas. Entretanto, também ficou evidenciada a importância de se realizar aulas práticas em laboratório como etapa fundamental de uma sequência didática sobre o conteúdo de microalgas, haja vista que os alunos enalteceram essa metodologia como fundante para a construção dos seus saberes.

\section{REFERÊNCIAS}

ADAMY, H. V.; CASSOL, A. P. V.; ELICKER, C.; MENEGHETTI, J.; SILVA, J. F. DA; OLIVEIRA, M. A. Sugestão de alternativas de materiais didáticos para o ensino de microalgas. Revista Eletrônica Científica da UERGS, v. 1, n. 1, p. 58-61, 2015. Acesso em: 11 de julho de 2020.

AMARAL, J. A., BEZERRA, C.S., CARMO, F.N.A., ALVES, N. T. O., MOURA, D. S., FERREIRA, R. G. E., PEREIRA, C. I. V. Construção e Avaliação de Modelos Didáticos Destinados ao Ensino-

Aprendizagem de Biologia. Instituto Federal do Rio Grande do Norte, 2010. Disponível em: <http://connepi.ifal.edu.br/ocs/index.php/connepi/CONNEPI2010/paper/view/1166>. Acesso em: 20 de março de 2020.

ANDRADE, M. L. F.; MASSABNI, V. G. O desenvolvimento de atividades práticas na escola: Um desafio para professores de Ciências. Ciência \& Educação. v. 17, n. 4, p. 835-854, 2011.

BICUDO, C. E. M., MENEZES, M. Gêneros de algas de águas Continentais do Brasil. Chave para identificação e descrições. 2. ed. São Carlos: RiMa. 2006. 
BRITO, A. C. S.; VALLIM, M. A.; Confecção de Modelos Didáticos de Microalgas: Uma Proposta de Utilização na Educação Básica. In: IV ENCONTRO NACIONAL DE ENSINO DE CIÊNCIAS DA SAÚDE E DO AMBIENTE, 2014, Niterói. Anais eletrônicos. Niterói: Universidade Federal Fluminense, 2014. Disponível em: <http://www.decb.uerj.br/arquivos/magui_181-748-1-PB.pdf>. Acesso em: 18 de março de 2020.

CARVALHO, A. M. P. de. O ensino de ciências e a proposição de sequências de ensino investigativas. In: . Ensino de Ciências por investigação: condições para implementação em sala de aula. 1.ed. São Paulo: Cengage Learning, 2013. Cap. 1, p. 1-20.

CERQUEIRA, J. B., FERREIRA, E. M. B. Recursos didáticos na educação especial. Revista Benjamin Constant. v. 5, n. 5. p. 49-55, 1996.

CHOW, F. (Org). Introdução a Biologia das Criptógamas. São Paulo, Instituto de Biociências da Universidade de São Paulo, Departamento de Botânica, 2007.

DERNER, R. B., OHSE, S., VILLELA, M., CARVALHO, S. M., FETT, R. Microalgas, produtos e aplicações. Ciência Rural. v. 36, n. 6, p. 1959-1967. 2006.

FERNANDES, V. de O.; SILVA, L. P. da; ARAÚJO, M. P. M. Sensibilização ambiental para alunos dos anos iniciais do ensino fundamental por meio da divulgação científica: desvelando os mistérios da Lagoa Mãe-Bá. Revista Brasileira De Educação Ambiental (RevBEA), v. 15, n. 1, p. 116-130, 2020. Disponível em: https://doi.org/10.34024/revbea.2020.v15.10228. Acesso em: 11 ago. 2020.

JUSTINA, L. A. D., FERLA, M. R. A utilização de modelos didáticos no ensino de Genética Exemplo de representação de compactação do DNA eucarioto. Arq Mudi, 2006. Disponível em:

<http://periodicos.uem.br/ojs/index.php/ArqMudi/article/viewFile/19924/10818>. Acesso em: 15 de maio de 2020.

KOBASHIGAWA, A. H., ATHAYDE, B. A. C. C., MATOS, K. F. O., CAMELO, M. H., FALCONI, S. Estação Ciência: Formação de educadores para o ensino de ciências nas séries iniciais do ensino fundamental. Estação Ciência/USP. Disponível em:

<http://200.144.189.54/dados/smm/_estacaocienciaformacaodeeducadoresparaoensinodecienciasn asseriesiniciaisdoensinofundamental.trabalho.pdf>. Acesso em: 30 de abril de 2020.

KRASILCHIK, M. Práticas do Ensino de Biologia. 4 ed. São Paulo: EDUSP; 2008.

LOURENÇO, S. O. Cultivo de Microalgas Marinhas: princípios e aplicações. 1 ed. São Carlos: RiMa. 2006.

MELLO J.M., DAGOSTIN, M.A.A., DAGOSTIN, A.L.A., KADOWAKI, M.K., BRANCALHÃO, R.M.C. Modelo didático para compreensão da estrutura da proteína. Arq Mudi, 2007. Disponível em:<http://periodicos.uem.br/ojs/index.php/ArqMudi/article/view/20000/10839>. Acesso em: 18 de março de 2020.

ORLANDO, T.C. LIMA, A.R., SILVA, A.M., FUZISSAKI, C.N., RAMOS, C.N., MACHADO, D. FERNANDES, F.F., LORENZI, J.C.C., LIMA, M.A., GARDIM, S. Planejamento e aplicação de modelos didáticos para abordagem de biologia celular e molecular no ensino médio por graduando de Ciências Biológicas. Revista Brasileira de Ensino de Bioquímica e Biologia Molecular. 2009. Disponível 25 em: <http://bioquimica.org.br/revista/ojs/index.php/REB/article/view/33/29>. Acesso em: 20 de março de 2020. 
PANOSSO, R., COSTA I. A. S., SOUZA, N. R., ATTAYDE, J. L., CUNHA, S. R. S., GOMES, F. C. F. G. Cianobactérias e cianotoxinas em reservatórios do estado do Rio Grande do Norte e o potencial controle das florações pela tilápia do Nilo (Oreochromis niloticus). Oecologia Brasiliensis, v. 11, n. 6, p.433-449. 2007.

ROSA, A. B. Aulas diferenciadas e seus efeitos na aprendizagem dos alunos: o que os professores de Biologia têm a dizer sobre isso? Trabalho de Conclusão de Curso de Ciências Biológicas. 43p. Universidade Federal do Rio Grande do Sul: Porto Alegre. 2012.

ROUND, F. E, CRAWFORD, R. M., MANN, D. G. The Diatoms - Biology \& morphology of the genera. 1 ed. Cambridge: Cambridge University. 1990.

SILVA, J. B.; VALLIM M. A. Estudo, desenvolvimento e produção de materiais didáticos para o ensino de biologia. Revista Aproximando, v. 1, n. 1, 2015.

SILVA, K. G., REZENDE, E. C. S., PEREIRA, E. N. P., MOURA, A. C. A., ALMEIDA, A. V. Uma Intervenção de Práticas e Modelização do Olho Humano e Suas Funcionalidades. Recife, 2009. Disponível em: < http://www.eventosufrpe.com.br/jepex2009/cd/resumos/r0261-1.pdf>. Acesso em: 16 de maio de 2020.

Submissão: 13/08/2020

Aceito: 23/09/2020

\footnotetext{
' Esta pesquisa foi desenvolvida por pesquisadores do Instituto Federal do Espírito Santo-Ifes, campus Santa Teresa, em parceria com o Lateac- Laboratório de Taxonomia e Ecologia de Algas Continentais da Universidade Federal do Espírito Santo.

ii Até a data 12 de agosto de 2020, data em que a revisão bibliográfica desse artigo foi concluída.

iii Célula especializada na fixação de nitrogênio do ambiente aquático, encontrada em filamentos de cianobactérias.

iv Célula diferenciada de filamentos de cianobactérias que surgem quando as condições são desfavoráveis para a sobrevivência (baixa luminosidade e mudança no $\mathrm{pH}$, por exemplo).

${ }^{\vee}$ Estrutura fotossensível presente em euglenófitas, responsável pela orientação desses organismos em direção aos focos de luz disponíveis na coluna d’água.

vi Organismos que apresentam envoltório nuclear (carioteca) e organelas membranosas. Exemplos deles são as algas, os protozoários, os fungos, as plantas e os animais.

vii Organismos que, por não apresentarem envoltório nuclear- carioteca, não apresentam material genético compartimentalizado. Também não apresentam organelas membranosas. Exemplos desses seres vivos são as bactérias e as cianobactérias.
} 